\title{
SELF-INCOMPATIBILITY PROTEINS IN PLANTS: DETECTION, GENETICS, AND POSSIBLE MODE OF ACTION*
}

\author{
M. E. NASRALLAH, J. T. BARBER and D. H. WALLACE \\ State University of New York, College at Cortland, N.Y., Department of Biology, Tulane University, \\ New Orleans, La., and Department of Plant Breeding and Biometry, Cornell University, Itaca, N.Y.
}

Received 6.ii.69

\section{INTRODUCTION}

THE exact physiological mechanisms underlying the self-incompatibility reaction in plants is still unknown. The work of Lewis (1952) on $S$ allele specific antigens in the pollen of Oenothera and the recent detection of similar $S$ allele specific antigens in stigmas of self-incompatible Brassica (Nasrallah and Wallace, 1967a) constitute a first step towards isolation and characterisation of the self-incompatibility controlling substances. 'These demonstrations of a molecular basis for self-incompatibility, coupled with an already sophisticated and extensive genetic analysis of the multiple allelic $S$ locus offer a rare opportunity to study gene action and control in higher plants. The $S$ alleles and corresponding $S$ antigens have definite and easily recognised phenotypic effects, thereby providing a unique system for the study of geneprotein-phenotype relationships (Nasrallah and Wallace, 1967a,b). These workers have established gene-antigen-incompatibility correlations but it remained to be determined whether the $S$ antigens are primary gene products (polypeptides).

\section{MATERIALS AND METHODS}

The homozygous Brassica oleracea var. capitata genotypes $S_{1} S_{1}, S_{2} S_{2}, S_{2}^{\prime} S_{2}^{\prime}$, $S_{3} S_{3}$ (referred to in the text as $S_{1}, S_{2}, S_{2}^{\prime}$, and $S_{3}$ ) and the immunoelectrophoresis and immunodiffusion techniques used were essentially identical to those described earlier (Nasrallah and Wallace, 1967a). Lines $S_{2}$ and $S_{2}^{\prime}$ are isogenic and phenotypically similar except that $S_{2}^{\prime}$ is homozygous for a dominant gene, probably a suppressor, that reduces the quantity of the $S$ antigen and results in self-fertility. Genotypes $H_{4}, H_{5}$, and $H_{6}$ are additional inbred cabbage lines supplied by Joseph Harris Company, Inc., Rochester, New York. Their exact $S$ allele genotype is not known but they breed true and each is presumed to be homozygous for a different $S$ allele. Each was found to be cross-compatible with $S_{1}, S_{2}$, and $S_{3}$. The antiserum used $\left(\mathrm{AHS}_{2}\right.$ ) was developed against $S_{2}$ stigmatic homogenates and was the same batch of antiserum used previously (Nasrallah and Wallace, 1967a, b). Stigmatic homogenates for acrylamide gel electrophoresis were prepared as follows: Approximately $75 \mathrm{mg}$. fresh weight of stigmas from each genotype were homogenised in the cold with tris-glycine buffer $(0.1 \mathrm{M}, p \mathrm{H} 8.3)$ using a mortar and pestle and acid washed sand. The resulting homogenates were transferred to $400-\mu l$. centrifuge tubes and centrifuged for 10 minutes at 15000 r.p.m. in a Beckman/Spinco Model 152 microfuge. Routinely, a 175- $\mu$ l. aliquot of each supernatant fluid was subjected to electrophoresis in 7.5 per cent. acrylamide gels at $p \mathrm{H} 5.0$ as described by Barber et al. (1967).

* Department of Biology Paper No. 28. 
Proteins thus separated were stained with 0.7 per cent. $(\mathrm{w} / \mathrm{v})$ amido black in 7 per cent. ( $\mathrm{v} / \mathrm{v}$ ) acetic acid and the results recorded by photographing the stained gels. In certain instances unstained gels of some extracts were used for immunodiffusion studies. In other instances, areas of peroxidase activity were located in the unstained gels by incubating these for 15 minutes at $25^{\circ} \mathrm{C}$. in a solution which consisted of 0.3 per cent. ( $\mathrm{w} / \mathrm{v}$ ) benzidine in 95 per cent. (v/v) ethyl alcohol mixed with an equal volume of a $1: 50$ dilution of 3 per cent. hydrogen peroxide (Gomori, 1952).

\section{Results}

Most proteins from the stigmatic homogenates were acidic in that they moved to the anode at $p \mathrm{H} 8.3$ under the conditions described by Steward et al. (1965). These patterns consisted of numerous protein bands with no discernible genotype specific differences. However, electrophoretic runs at $p \mathrm{H} 5.0$ revealed genotype specific patterns and pattern differences that were consistently observed in separate runs on homogenates prepared from different plants of the same genotype as shown for $S_{1}$ and $S_{2}$ in Plate I, fig. 1 .

Plate I, fig. 2 shows patterns obtained with immunoelectrophoresis ( $p \mathrm{H}$ 8.2) where $S_{2}$ and $S_{2}^{\prime}$ proteins were reacted against unabsorbed antiserum $\left(\mathrm{AHS}_{2}\right)$. The precipitation band on the cathode side of the source well was identified as the antigenic $S_{2}$ band of the earlier study (Nasrallah and Wallace, 1967a), since it was present in both $S_{2}$ and $S_{2}^{\prime}$ stigmatic homogenates but was absent from those of other genotypes. As previously reported, the $S_{2}$ homogenates had a higher concentration of $S_{2}$ antigen than did the $S_{2}^{\prime}$ homogenates. This was indicated by the greater intensity of the precipitation band opposite $S_{2}$ as compared to $S_{2}^{\prime}$.

An examination by acrylamide gel electrophoresis of basic proteins in stigmas of $S_{2}$ and $S_{2}^{\prime}$ is shown in Plate I, fig. 3. The electrophoretic patterns indicate a lesser quantity of protein in bands $(a)$ and $(b)$ for $S_{2}^{\prime}$ than for $S_{2}$ even though a greater quantity of $S_{2}^{\prime}$ homogenate $(200 \mu l$. as compared with $175 \mu \mathrm{l}$. for $S_{2}$ ) was used in order to favour the appearance of these weak bands in $S_{2}^{\prime}$. Since immunodiffusion (Nasrallah and Wallace, 1967a) had previously indicated less $S_{2}$ antigen in $S_{2}^{\prime \prime}$ than $S_{2}$, it seemed likely that band $(a)$ or $(b)$ might correspond to the antigenic $S_{2}$ band. Acrylamide gel electrophoresis and immunodiffusion techniques were combined to test this possibility. The proteins extracted from $S_{2}$ and $S_{2}^{\prime}$ were separated on acrylamide gels and instead of staining with amido black the gels were placed on an agar layer parallel to and at a distance of $0.7 \mathrm{~cm}$. from a trough containing antiserum $\left(\mathrm{AHS}_{2}\right)$. The separated proteins diffused from the acrylamide gel into the agar and reacted with the antibodies as shown in plate I, fig. 4. An antigenic $S_{2}$ precipitation band appeared in a position which seems to correspond very closely with the $(b)$ band of plate I, fig. 3 . No precipitation band was visible for $S_{1}$.

\section{(i) Genotype specific proteins}

The acrylamide gel electrophoresis patterns of plate II, fig. 5 show qualitative differences among the six genotypes tested. Genotypes $S_{1}, S_{2}$, and $S_{3}$ were each previously shown to have an $S$ allele specific antigen (Nasrallah and Wallace, 1967a). Acrylamide gel electrophoresis gave simi- 


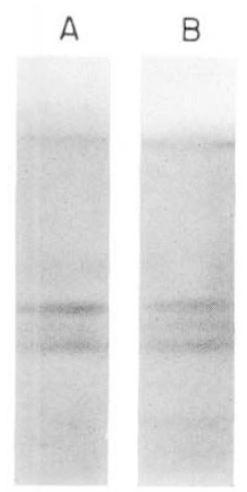

$\mathrm{S}_{1}$

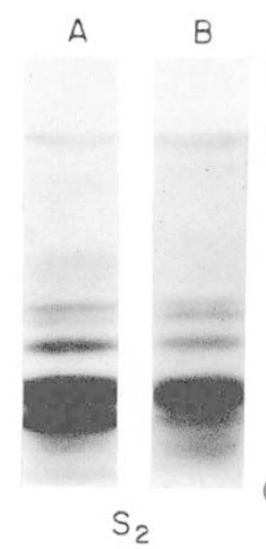

$\mathrm{S}_{2}$

\section{ORIGIN}

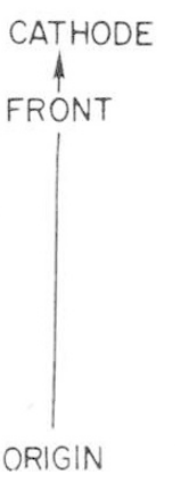

\section{2}
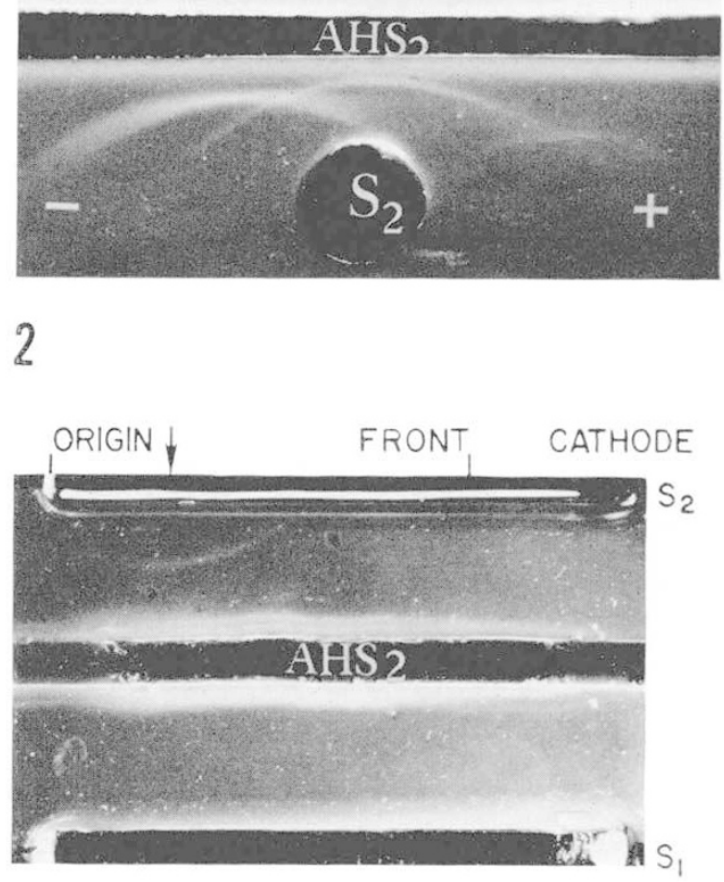

4

FIG. 1.-Electrophoretic separations on acrylamide gels of the basic proteins from stigmatic homogenates of cabbages homozygous for $S$ alleles $S_{1}$ and $S_{2}$. Reproducibility of the soluble protein patterns is shown in that the (B) separations were made from different plants and one year later than the (A) separations.

FIG. 2.- Immunoelectrophoretic separations in barbital buffer at $p \mathrm{H} 8.2 \mathrm{cf}$ stigmatic homogenates of genotypes $S_{2}$ and $S_{2}^{\prime}$. The homogenates were electrophoretically separated in agar and then tested against antiserum $\left(\mathrm{AHS}_{2}\right.$ ) produced against $S_{2}$ which was placed in the centre trough. The precipitation band to the cathode side of the source wells is stronger in $S_{2}$ than $S_{2}^{\prime}$, indicating a greater concentration of the $S_{2}$ antigen in genotype $S_{2}$. This antigen was absent (cf. fig. 4) from homogenates of $S$ allele genotypes other than $S_{2}$ and $S_{2}^{\prime}$.

Fic. 3.--Electrophoretic separations on acrylamide gels of the $S_{2}$ and $S_{2}^{\prime}$ basic stigmatic proteins extracted by tris-glycine buffer $(0.1 \mathrm{M}, p \mathrm{H} 8.3)$. A lower concentration of protein in bands $(a)$ and $(b)$ is indicated for $S_{2}^{\prime}$ than for $S_{2}$ even though $200 \mu \mathrm{l}$. of $S_{2}^{\prime}$ extract was used as compared to $175 \mu \mathrm{l}$. for $S_{2}$ in order to favour development of these weak bands in $S_{2}^{\prime}$.

Fic. 4.--Serological response of electrophoretically separated basic proteins from $S_{1}$ and $S_{2}$ stigmatic homogenates. The proteins were separated on acrylamide gels and the unstained gels were placed on an agar layer parallel to a trough containing antiserum $\left(\mathrm{AHS}_{2}\right)$. The precipitation band indicated by the arrow appears in $S_{2}$ separations at a position opposite band (b) of fig. 3 but does not appear in the $S_{1}$ separations or those of other genotypes. 

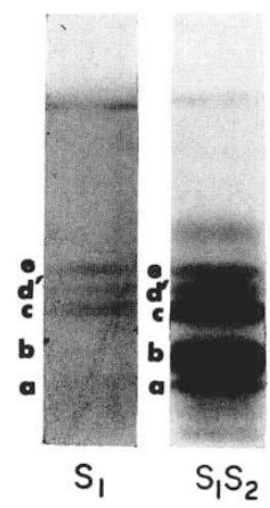

5

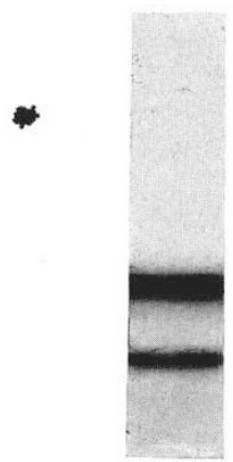

$\mathrm{S}_{1}$

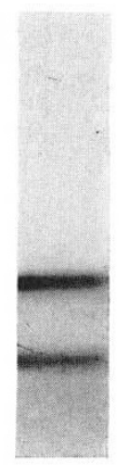

$\mathrm{S}_{2}$

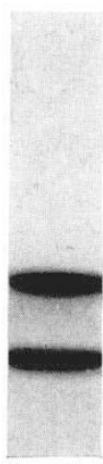

$\mathrm{S}_{3}$

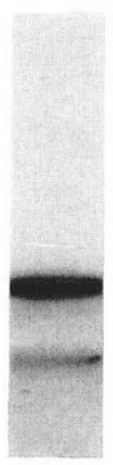

$\mathrm{S}_{1} \mathrm{~S}_{2}$

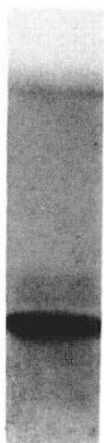

$\mathrm{H}_{4}$

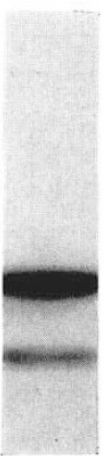

$S_{1} S_{3}$

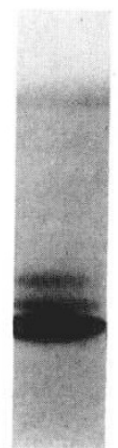

$\mathrm{H}_{5}$

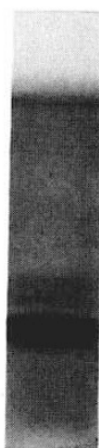

$\mathrm{H}_{6}$

\section{CATHODE} $\uparrow$ FRONT

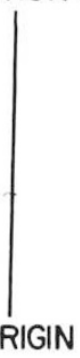

6

FIG. 5.-Electrophoretic separations on acrylamide gels of the basic proteins from stigmatic homogenates of six homozygous and two heterozygous $S$ allele genotypes extracted by tris-glycine buffer $(0 \cdot 1 \mathrm{M}, p \mathrm{H} 8 \cdot 3)$. A unique band occurs for each homozygous genotype and the unique bands of both parents appear in the hybrid genotypes.

FIG. 6.-Peroxidase activity of the stigmatic basic proteins extracted by tris-glycine buffer $(0 \cdot 1 \mathrm{M}, p \mathrm{H} 8 \cdot 3)$. The proteins were separated by electrophoresis on acrylamide gels. Benzidine was used as the hydrogen donor to stain proteins having peroxidase activity. 
lar results in that, in addition to bands occupying corresponding positions in several genotypes, there were bands unique to specific genotypes. With reference to $S_{2}, S_{1}$ has a weak band at position $(a)$, the antigenic $S_{2}$ band at position $(b)$ is practically missing, the bands at positions $(c)$ and $(e)$ correspond to those of $S_{2}$, but $S_{1}$ has a band at $\left(d^{\prime}\right)$ that does not occur in $S_{2}$. Thus, $S_{1}$ differs from $S_{2}$ in being deficient for the antigenic $S_{2}$ band at position $(b)$ and also in possessing a unique band at position $\left(d^{\prime}\right)$. Genotype $S_{3}$ has a very faint band at position (a), bands corresponding to those of $S_{1}$ and $S_{2}$ at positions $(c)$ and $(e)$, lacks bands at positions $(d)$ and $\left(d^{\prime}\right)$, but has a unique band at position $\left(b^{\prime}\right)$. Genotypes $H_{4}, H_{5}$, and $H_{6}$ have not been previously studied and are included for comparison. All differ from $S_{1}, S_{2}$, and $S_{3}$ in overall pattern; $H_{4}$ and $H_{6}$ appeared similar but slightly different from $H_{5}$.

\section{(ii) Protein patterns of hybrids}

Plate II, fig. 5 also shows protein patterns of hybrids $S_{1} S_{2}$ and $S_{2} S_{3}$ alongside those of their parents. $S_{1} S_{2}$ has a band at position $(b)$ corresponding with the unique $(b)$ band of the $S_{2}$ parent and a band at $\left(d^{\prime}\right)$ corresponding with the unique $\left(d^{\prime}\right)$ band of the $S_{1}$ parent. $S_{2} S_{3}$ has bands at positions $(b)$ and $\left(b^{\prime}\right)$ corresponding respectively to the unique bands of parents $S_{2}$ and $S_{3}$. Thus, the hybrids exhibit the unique electrophoretically identified proteins of both of their parents, as the hybrids exhibited the unique $S$ antigens of both parents as demonstrated by immunodiffusion (Nasrallah and Wallace, 1967a). The hybrid $S_{1} S_{3}$ was not studied because of unavailability when these tests were made.

\section{(iii) Peroxidase activity}

During the course of this investigation, Pandey (1967) reported that the $S$ gene of Nicotiana seemingly codes for polypeptides with peroxidase activity. The $S$ alleles that Pandey worked with were found to produce specific peroxidase bands. Tests for peroxidase activity were therefore conducted on several $S$ allele genotypes of cabbage as shown in plate II, fig. 6. Peroxidase activity was localised at two equivalent and corresponding positions in all genotypes. The use of a hydrogen donor other than benzidine might have revealed different peroxidase patterns (Macko et al., 1967). However, using benzidine as did Pandey, no differences in electrophoretic mobilities of peroxidases could be detected. The possibility of nonspecific association between peroxidase enzymes and " $S$ " proteins should also be considered.

\section{Discussion}

Using acrylamide gel electrophoresis, qualitative and quantitative differences in protein patterns were demonstrated in stigmatic homogenates from several $S$ allele genotypes of $B$. oleracea. Three of these genotypes, $S_{1}$, $S_{2}$, and $S_{3}$, were studied extensively and displayed genotype specific bands. The same genotypes were each found to have present in their stigmas a unique antigen (Nasrallah and Wallace, 1967a). Stigmatic homogenates from the hybrids $S_{1} S_{2}$ and $S_{2} S_{3}$ exhibited the $S$ allele specific bands of both parents. In the earlier study, these hybrids were also shown to possess both parental antigens. Furthermore, comparison of acrylamide gel patterns of the isogenic lines $S_{2}$ and $S_{2}^{\prime}$ revealed a quantitative difference in the $S_{2}$ band. Similar differences were also recognisable with immunodiffusion and 
immunoelectrophoretic methods. The agreement between acrylamide gel results and those obtained by immunodiffusion and/or a combination of the two techniques lead us to conclude that the " $\mathrm{S}$ " antigens are proteins; presumably primary gene products of the $S$ alleles.

A hypothesis derived from these results and current concepts of the genetic code assumes a one to one relationship between $S$ alleles and $S$ proteins. The $S$ proteins vary by amino acid substitutions that lead to simultaneous differences in electrophoretic mobilities, antigenic determinants ( $c f$. Ingram, 1963; Iino, 1965), and phenotypic expression of self-incompatibility: Justification for this hypothesis comes from findings that antisera can recognise proteins which differ by only one amino acid substitution as demonstrated for human haemoglobins $A, S$, and $C$ (Boerma et al., 1964), for haemoglobins $A_{2}$ and $B_{2}$ (Jones et al., 1965), and for immunoglobulins (Baglioni et al., 1966). Schreffler (1967) has recently reviewed the structural basis and genetic control of cellular antigens. We have no evidence suggesting association with carbohydrates, or polymerisation of protein subunits to form molecular aggregates as was postulated by Lewis (1963). It is assumed that variations in DNA coding of the different $S$ alleles lead to structural modifications of the $S$ proteins as specified by the $S$ alleles. Many structural variations are possible since several amino acid substitution sites could potentially lead to antigenic polypeptide differences. It has already been demonstrated that extensive protein variability does result from amino acid substitution, more than 22 variants of $\alpha$-haemoglobin and 43 variants of $\beta$-haemoglobin having been found in humans (Neurath et al., 1967). Thus, the unresolved question of origin of $S$ alleles (Pandey, 1967) is amenable to direct experimentation by comparing the amino acid sequences of incompatibility proteins specified by different $S$ alleles.

Heritability of these $S$ allele specific proteins was demonstrated by the presence in $S$ allele heterozygotes of the $S$ allele specific proteins of both homozygous parents. The two parental $S$ antigens were previously demonstrated (Nasrallah and Wallace, 1967a) to be present in stigmas of heterozygous $F_{1}$ plants, to segregate in the $F_{2}$ as expected for control by a single gene, and to correlate perfectly with phenotypic expression of self-incompatibility.

As for their mode of action in phenotypic expression of incompatibility, we postulate that the $S$ proteins of the stigma act as regulator substances. These diffuse into the pollen grains and recognise appropriate $S$ genotypes thus "shutting off" the synthesis of enzymes needed for pollen germination and tube growth. The $S$ proteins were indeed found to diffuse readily from uninjured stigmas (Nasrallah and Wallace, 1967b). As for penetrability of these basic proteins into pollen grains, recent reports indicate that cells readily take up cationic proteins of large molecular weights (Ryser, 1968). Preliminary estimates (unpublished data) indicate a molecular weight of about 150000 for the $S_{2}$ protein. The hypothesised mode of action for the $S$ proteins can be tested by developing labeled $S$ proteins and identifying the site of action in compatible and incompatible pollinations.

\section{Summary}

1. Acrylamide gel electrophoresis and immunodiffusion were used to study the buffer soluble basic proteins of stigmatic homogenates of several $S$ allele genotypes of cabbage. 
2. Each $S$ allele genotype had a different electrophoretic protein band pattern.

3. Each of the genotypes $S_{1} S_{1}, S_{2} S_{2}$, and $S_{3} S_{3}$ had a unique electrophoretically separated protein band.

4. The unique protein band of genotypes $S_{2}$ and $S_{2}^{\prime}$ was shown to be the $S$ allele specific antigen previously identified by immunodiffusion.

5. The electrophoretically separated $S$ allele specific proteins were shown to be heritable by the presence in heterozygous genotypes of the unique proteins of each of the two homozygous parents.

6. It is hypothesised that $S$ allele specific proteins differ by amino acid substitutions.

7. It is postulated that the basic $S$ proteins act as regulators of enzymes needed for pollen germination and tube growth.

Acknowledgments.-The work was supported by a grant awarded by the National Science Foundation (Grant GB 4319) and by a research fellowship awarded by the Research Foundation of the State University of New York. The authors acknowledge the assistance of Dr J. A. Gustafson of Cortland College and of Drs Bruce Wallace and Harry Stinson of Cornell University for reading and improving the manuscript.

\section{REFERENCES}

BAGLIONI, C., zONTA, L. A., GIOLI, D., AND GARBonara, A. 1966. Allelic antigenic factor Inv (a) of the light chains of human immunoglobulins: chemical basis. Science, 152, 1517. BARBER, J. T., WOOD, H. L., AND STEWARD, F. C. 1967. The separation of the proteins of wheat by acrylamide gel electrophoresis with special reference to mottled and unmottled wheat. Can. 7. Bot., 45, 5.

boerma, F. W., hunsman, T. H. J., Dozy, A., hartmaus, F., AND Devries, N. 1964. Serologic investigations of human hemoglobins. II. Antibodies produced by isolated human hemoglobin types with known structural differences. F. Lab. Clin. Med., 63, 264.

Gomori, G. 1952. Microscopic Histochemistry. The University of Chicago Press, Chicago, Illinois.

InNo, T. 1965. Genetics of flagellar antigen in Salmonella. Proc. 11th Int. Congr. Genet., 3, 731. Ingram, v. M. 1963. The Hemoglobins in Genetics and Evolution. Columbia University Press, New York.

JONES, R. T., BOERMA, F. W., AND HUISMAN, T. H. J. 1965. Structural characterization of $\mathrm{HbA}_{2}^{\prime}\left(\mathrm{B}_{2}\right): a_{2} \delta_{2} 16 \mathrm{Arg}$. Presented at Annual Meeting, Amer. Soc. Hum. Genet.; 1965. (See Amer. 7. Hum. Gen., 17, 511.)

LEwIs, D. 1952. Serological reactions of pollen incompatibility substances. Proc. Roy. Soc. (Lond.) $B, 140,127$.

LEwIs, D, 1963. A protein dimer hypothesis on incompatibility. Proc. 11th Int. Congr. Genet., 2, 657.

Macko, V., honold, G. R., AND stahmanN, M. A. 1967. Soluble proteins and multiple enzyme forms in early growth of wheat. Phytochemstry, 6, 465.

NASRALLAH, M. E., AND WALLAGE, D. H. 1967a. Immunogenetics of self-incompatibility in Brassica oleracea L. Heredity, 22, 519.

NASRALLAH, M. E., AND WALLAGE, D. H. 1967b. Immunochemical detection of antigens in self-incompatibility genotypes of cabbage. Nature, 213, 700.

NEURATH, H., WALSH, K. A., AND WINTER, W. P. 1967. Evolution of structure and function of proteases. Science, $158,1638$.

PANDEY, K. K. 1967. Origin of genetic variability: Combinations of peroxidase isozymes determine multiple allelism of the $S$ gene. Nature, 213, 669 .

RYSER, H. J. P. 1968. Uptake of protein by mammalian cells: An underdeveloped area. Science, 159, 390.

SHREFfler, D. C. 1967. Molecular aspects of immunogenetics. Ann. Rev. of Genetics, $1,163$. STEWARD, F. C., LYNDON, R. F., AND BARBER, J. T. 1965. Acrylamide gel electrophoresis of soluble plant proteins: A study on pea seedlings in relation to development. Amer. $\mathcal{J}$. Bot., 52, 155. 